\title{
Identifikasi Karakter Kerja Keras dalam Mata Pelajaran IPA di SMPN 3 Batanghari
}

\author{
Lasmita $^{1}$ \\ ${ }^{1}$ SMPN 3 Batanghari, Jambi, Indonesia
}

\begin{tabular}{l} 
Article Info \\
\hline Article history: \\
Received Dec 27, 2019 \\
Revised Dec 29 2019 \\
Accepted Dec 31, 2019 \\
\hline
\end{tabular}

\section{Keywords:}

Kerja Keras

Sikap

IPA

\begin{abstract}
Tujuan Penelitian: Penelitian ini bertujuan untuk mendeskripsikan karakter kerja keras siswa di SMPN 3 Batanghari melalui enam indikator dari angket kerja keras siswa yaitu Menciptakan kondisi etos kerja, Pantang menyerah, Selalu fokus pada pelajaran, Mengerjakan semua tugas kelas dengan baik dan tepat waktu, Tidak putus asa dalam belajar, Berusaha menyelesaikan tugasnya hingga tuntas dan Menciptakan suasana belajar yang memacu daya tahan kerja.
\end{abstract}

Metodologi: Desain penelitian yang digunakan dalam penelitian ini adalah kuantitatif dengan jenis penelitian survei. Teknik pengambilan sampel yang digunakan ialah total sampling dengan jumlah sampel untuk pengisian kuesioner sebagai teknik pengambilan total sampling sebanyak 160 siswa di SMPN 3 Batanghari. Instrumen yang digunakan merupakan adopsi dari berbagai penelitian dengan menggunakan enam indikator angket kerja keras siswa

Temuan Utama: Berdasarkan hasil analisa data diperoleh bahwa pada indikator pertama siswa dominan berkategori baik, lalu indikator kedua dominan berkategori baik, kemudian indikator ketiga siswa dominan berkategori baik, selanjutnya indikator keempat siswa dominan berkategori baik dan indikator kelima serta keenam siswa dominan berkategori sangat baik. Sehingga karakter kerja keras siswa di SMPN 3 Batanghari berada pada kategori baik

Keterbaruan Penelitian: Keterbaruan penelitian ini terdapat pada Indikator yang digunakan, adapun indicator ini meliputi; Menciptakan kondisi etos kerja, Pantang menyerah, Selalu fokus pada pelajaran, Mengerjakan semua tugas kelas dengan baik dan tepat waktu, Tidak putus asa dalam belajar, Berusaha menyelesaikan tugasnya hingga tuntas dan Menciptakan suasana belajar yang memacu daya tahan kerja

This is an open access article under the $\mathrm{CC} B Y-N C$ license

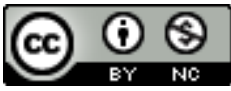

\section{Corresponding Author:}

Lasmita,

Guru Fisika, SMPN 3 Batang Hari,

Jl. Rengas Condong, Muaro Bulian, Kabupaten Batang Hari, Jambi, 36612, Indonesia

Email: lestari321@gmail.com

\section{PENDAHULUAN}

Di era serba digital seperti saat ini, pendidikan merupakan salah satu faktor penting yang perlu diperhatikan dalam kehidupan karena pendidikan dapat dijadikan sebagai alat perubahan sosial dan investasi dalam pembangunan nasional. Fokus utama dalam dunia pendidikan adalah manusia; dalam hal ini adalah peserta didik karena dengan adanya pendidikan, peserta didik didorong untuk terlibat dalam proses mengubah kehidupannya ke arah yang lebih baik, mengembangkan kepercayaan diri sendiri, 
mengembangkan rasa ingin tahu, serta meningkatkan pengetahuan dan ketrampilan yang telah dimilikinya, sehingga dapat berfungsi untuk peningkatan kualitas hidup pribadi dan masyarakat [1]. Education is not only a media to pass on culture to the next genera-tion, but is also expected to be able to change and develop the life pattern of the nation in a better direction Education is also a long-term investment that we must prepare innovation. It should be understandable to colleagues from a broad range of scientific disciplines. in order for us to have a better life in the future [2-3]. Perubahan sosial yang terjadi secara berkala mengikuti arus perkembangan zaman. Education is an on going process that aims to increase the quality of human resources. Formal education in Indonesia starts from primary education, secondary education and tertiary education [4-6].

Pada tingkatan kedua yang selanjutnya disebut Sekolah Menengah Pertama (SMP) merupakan jenjang pendidikan dasar formal setelah menyelesaikan pendidikan sekolah dasar atau yang sederajatnya. Siswa sedikit demi sedikit mampu mengendalikan dirinya dalam berpikir secara ilmiah. Pada masa ini siswa mengalami masa transisi dari anak-anak menuju dewasa yang sulit untuk mengendalikan emosi pada dirinya dalam menghadapi segala bentuk permasalahan dalam kehidupan. Keberlanjutan pendidikan di lembaga pendidikan tersebut berkaitan erat dengan kurikulum. Saat ini kurikulum yang digunakan adalah kurikulum 2013 revisi yang lebih menekankan pada pembentukan karakter. Sehubungan dengan hal itu untuk menciptakan sumberdaya manusia yang mampu mengontrol diri dalam menghadapi perkembangan zaman dan arus globalisasi juga diperlukan penanaman karakter pada diri siswa sejak dibangku sekolah melalui pendidikan karakter. Character education in order to help students not only to become smart but also to become good [7]. Pendidikan karakter merupakan usaha secara sengaja dari seluruh dimensi kehidupan sosial untuk membantu pembentukan karakter secara optimal [8].

Terdapat 18 karakter yang harus ditanamkan dalam diri siswa, salah satu nya adalah kerja keras. Kerja keras adalah kegiatan yang dikerjakan secara sungguh-sungguh tanpa mengenal lelah atau berhenti sebelum target kerja tercapai dan selalu mengutamakan atau memperhatikan kepuasan hasil pada setiap kegiatan yang dilakukan [9]. Artinya kerja keras merupakan usaha yang dilakukan dengan sungguh-sungguh agar mendapatkan hasil yang optimal. Siswa yang bekerja keras dalam proses pembelajaran biasanya akan selalu disiplin dalam menyelesaikan tugas-tugasnya selain itu ketika mendapatkan suatu hambatan ketika menyelesaikan persoalan siswa tidak akan mudah menyerah begitu saja melainkan akan berusaha semaksimal mungkin untuk menemukan solusi penyelesaiannya.

Karakter kerja keras pada diri siswa dapat di kembangkan dalam matapelajaran IPA. Natural Science is the learning process which is highly related to the environment and the regularity of the universe created by God the almighty [10]. Matapelajaran IPA di SMP dapat berkontribusi untuk menjadikan siswa mampu menjadi generasi yang memiliki karakter dalam kehidupan maupun lingkungannya. Sebab, nilai karakter dapat kita pandang melalui aspek intelektual dan moral. Intelektual menyiapkan kondisi mental dimana individu dapat memahami dan memilih suatu orientasi secara benar. Begitu juga moral akan menshahihkan tindakan-tindakan yang baik sehingga menjadi ciri kepribadian dalam berperilaku [11]. Matapelajaran IPA tergolong kedalam matapelajaran yang abstrak dan sulit dimengerti serta erat kaitannya dengan alam semesta sehingga dengan memahami konsep lebih dalam dapat membantu siswa meningkatkan kemampuannya dalam memahami matapelajaran IPA. Oleh karena itu sangat dibutuhkan usaha yang lebih keras agar dapat memahami konsep IPA. Rendahnya kemampuan berpikir siswa ini antara lain dikarenakan pembelajaran yang diterapkan di sekolah masih didominasi oleh guru sehingga kurang melatih kemampuan berpikir pada siswa [12]. Proses pembelajaran IPA masih didominasi oleh guru, pembelajaran cenderung menghapal daripada mengembangkan daya pikir sehingga siswa lemah dalam menyampaikan gagasannya sendiri, lemah dalam menganalisis, serta bergantung pada orang lain dibandingkan bertanggung jawab terhadap pilihannya sendiri [13].

Untuk mengukur kerja keras siswa dalam matapelajaran IPA dibutuhkan suau indikator. Ada 6 indikator yang digunakan yaitu:

1) Menciptakan kondisi etos kerja, pantang menyerah

2) Selalu fokus pada pelajaran

3) Mengerjakan semua tugas kelas selesai dengan baik pada waktu yang telah ditetapkan

4) Tidak putus asa dalam menghadapi kesulitan dalam belajar

5) Berusaha menyelesaikan tugasnya hingga tuntas

6) Mencipatakan suasana belajar yang memacu daya tahan kerja

Tujuan penelitian ini adalah untuk mendeskripsikan karakter kerja keras dalam mata pelajaran IPA di SMPN 3 Batanghari ditinjau melalui 6 indikator yang telah dipaparkan diatas sehingga mampu meningkatkan kerja keras siswa pada mata pelajaran IPA. Dalam penelitian ini, pertanyaan yang ditujukan ialah: Bagaimana deskripsi kerja keras siswa ditinjau dari 6 indikator karakter kerja keras pada matapelajaran IPA di SMPN 3 Batanghari?

ISEJ. Vol. 1, No. 1, Januari 2020: 07 - 15 


\section{METODE PENELITIAN}

Desain penelitian yang digunakan adalah kuantitatif dengan jenis penelitian survei. A survey is a quantitative research procedure in which the researcher administers survey of samples or in the entire population of people describe attitude, opinion, behavior, or specific characteristics of the population [14]. Penelitian ini bertujuan untuk mendeskripsikan kerja keras siswa pada matapelajaran IPA di SMPN 3 Batanghari.

Teknik pengambilan sampel yang digunakan ialah total sampling. Hal ini dilakukan karena peneliti ingin mendeskripsikan secara keseluruhan kerja keras siswa pada matapelajaran IPA di SMPN 3 Batanghari dengan jumlah sampel untuk pengisian kuesioner sebagai teknik pengambilan total sampling sebanyak 160 siswa.

Instrumen penelitian yang digunakan peneliti adalah angket. Angket yang digunakan merupakan angket tertutup. The respondent must choose from a set of given answers. These tend to be quick to answer, easy to code and require no special writing skills from the respondent. However, they do limit the range of possible answers [15]. Skala yang digunakan pada instrumen angket kerja keras adalah skala likert lima poin yang terdiri dari STS=sangat tidak setuju, TS=tidak setuju, N=netral, S=setuju, SS=sangat setuju. [16] skala likert adalah skala yang dapat dipergunakam untuk mengukur sikap, pendapat, atau presepsi seseorang atau sekelompok orang tentang satu variable, konsep atau gejala atau fenomena pendidikan Angket kerja keras di adaptasi dari penelitian [17] dan penelitian [18] Berikut ini adalah tabel yang menjelas kategori instrumen angket kerja keras.

Tabel 1. Kategori Angket Kerja Keras

\begin{tabular}{|c|c|c|c|c|c|}
\hline \multirow[b]{2}{*}{ Kategori } & \multicolumn{5}{|c|}{ Interval Indikator } \\
\hline & $\begin{array}{l}\text { Menciptakan } \\
\text { kondisi etos kerja, } \\
\text { pantang menyerah }\end{array}$ & $\begin{array}{l}\text { Selalu fokus pada pelajaran } \\
\text { dan Berusaha menyelesaikan } \\
\text { tugasnya hingga tuntas }\end{array}$ & $\begin{array}{l}\text { Mengerjakan semua tugas } \\
\text { kelas selesai dengan baik } \\
\text { pada waktu yang telah } \\
\text { ditetapkan dan Mencipatakan } \\
\text { suasana belajar yang memacu } \\
\text { daya tahan kerja }\end{array}$ & $\begin{array}{l}\text { Tidak putus } \\
\text { menghadapi } \\
\text { dalam belajar }\end{array}$ & $\begin{array}{l}\text { asa dalam } \\
\text { kesulitan }\end{array}$ \\
\hline $\begin{array}{l}\text { Sangat tidak } \\
\text { setuju }\end{array}$ & $13,0-23,4$ & $4,0-7,2$ & $2,0-3,6$ & $5,0-9,0$ & \\
\hline tidak setuju & $23,5-33,8$ & $7,3-10,4$ & $3,7-5,2$ & $9,1-13,0$ & \\
\hline Netral & $33,9-44,2$ & $10,5-13,6$ & $5,3-6,8$ & $13,1-17,0$ & \\
\hline Setuju & $44,3-54,6$ & $13,7-16,8$ & $6,9-8,4$ & $17,1-21,0$ & \\
\hline Sangat Setuju & $54,7-65,0$ & $16,9-20,0$ & $8,5-10$ & $21,1-25,0$ & \\
\hline
\end{tabular}

Adapun prosedur yang digunakan dalam penelitian ini adalah dimulai dengan menyebarkan kuesioner lalu analisis data angket kerja keras kemudian melanjutkan dengan mentranskip seluruh data yang diperoleh selama penelitian berlangsung

Tabel 2 Pernyataan dan Indikator Kerja Keras pada Matapelajaran IPA

\begin{tabular}{|c|c|c|c|c|}
\hline \multirow{2}{*}{ Variabel } & \multirow{2}{*}{ Indikator } & \multicolumn{2}{|l|}{ Pernyataan } & \multirow{2}{*}{ Jumlah Item } \\
\hline & & $(+)$ & $(-)$ & \\
\hline \multirow{6}{*}{$\begin{array}{l}\text { Kerja Keras pada } \\
\text { Matapelajaran } \\
\text { IPA }\end{array}$} & $\begin{array}{l}\text { Menciptakan kondisi etos kerja, pantang } \\
\text { menyerah }\end{array}$ & $\begin{array}{l}2,3,4,5,8,9,10,12,16,22,24,26 \\
, 30\end{array}$ & 0 & 13 \\
\hline & Selalu fokus pada pelajaran & 17,20 & 18,27 & 5 \\
\hline & $\begin{array}{l}\text { Mengerjakan semua tugas kelas selesai } \\
\text { dengan baik pada waktu yang telah } \\
\text { ditetapkan }\end{array}$ & 19,23 & 0 & 2 \\
\hline & $\begin{array}{l}\text { Tidak putus asa dalam menghadapi kesulitan } \\
\text { dalam belajar }\end{array}$ & 11,21 & $7,28,29$ & 5 \\
\hline & $\begin{array}{l}\text { Berusaha menyelesaikan tugasnya hingga } \\
\text { tuntas }\end{array}$ & $6,13,14,15$ & 0 & 4 \\
\hline & $\begin{array}{l}\text { Mencipatakan suasana belajar yang memacu } \\
\text { daya tahan kerja }\end{array}$ & 1,25 & 0 & 2 \\
\hline
\end{tabular}

Analisis data yang digunakan pada penelitian ini ialah analisis statistic deskriptif berupa mean, median dan modus. Teknik analisa data yang digunakan dibantu dengan program IBM SPSS Statistic 22.0. 


\section{HASIL DAN PEMBAHASAN}

\subsection{Hasil}

Keterbaharuan penelitian ini adalah indikator yang digunakan untuk mendeskripsikan karakter kerja keras siswa di SMPN 3 Batanghari. Indikator yang digunakan adalah Menciptakan kondisi etos kerja, Pantang menyerah, Selalu fokus pada pelajaran, Mengerjakan semua tugas kelas dengan baik dan tepat waktu, Tidak putus asa dalam belajar, Berusaha menyelesaikan tugasnya hingga tuntas dan Menciptakan suasana belajar yang memacu daya tahan kerja.. Untuk hasil penelitian dan diskusi keenam indikator ini adalah sebagai berikut

Tabel 3 Menciptakan Kondisi Etos Kerja dan Pantang Menyerah pada Matapelajaran IPA di SMPN 3 Batanghari

\begin{tabular}{ccccccccc}
\hline Rentang & Kerja Keras & Jumlah & $\%$ & Mean & Median & Modus & Min & Max \\
\hline $13,0-23,4$ & Sangat tidak & 0 & 0 & & & & & \\
$23,5-33,8$ & Setuju & Tidak Setuju & 0 & 0 & & & & \\
$33,9-44,2$ & Netral & 15 & 9,4 & 51,8 & 52,0 & 50,0 & 37,0 & 64,0 \\
$44,3-54,6$ & Setuju & 95 & 59,4 & & & & \\
$54,7-65,0$ & Sangat Setuju & 50 & 31,3 & & & &
\end{tabular}

Hasil analisis data kerja keras dalam matapelajaran IPA di SMPN 3 Batanghari pada indikator Menciptakan Kondisi Etos Kerja dan Pantang Menyerah di deskripsikan pada tabel 3 yang memperlihatkan bahwa respon siswa berkategori sangat baik sebanyak 31,3\% (50 dari 160 siswa). Lalu kategori baik sebanyak 59,4\% (95 dari 160 siswa), kategori cukup 9,4\% (15 dari 160 siswa), kategori tidak baik 0\% (0 dari 160 siswa) dan kategori sangat tidak baik yaitu 0\% (0 dari 160 siswa). Rata-rata skor yang diperoleh siswa adalah 51,8 dengan skor yang paling banyak diperoleh adalah 50,0 dimana skor minimalnya 37,0 dan skor maksimal 64,0. Dengan demikian berdasarkan hasil analisis data angket tabel 3 yaitu kerja keras dalam matapelajaran IPA di SMPN 3 Batanghari pada indikator ini memperlihatkan bahwa siswa lebih dominan berkategori baik.

Tabel 4 Selalu Fokus pada Matapelajaran IPA di SMPN 3 Batangahari

\begin{tabular}{|c|c|c|c|c|c|c|c|c|}
\hline Rentang & Kerja Keras & Jumlah & $\%$ & Mean & Median & Modus & Min & Max \\
\hline $4,0-7,2$ & $\begin{array}{l}\text { Sangat tidak } \\
\text { Setuju }\end{array}$ & 0 & 0 & & & & & \\
\hline $7,3-10,4$ & Tidak Setuju & 11 & 6,9 & & & & & \\
\hline $10,5-13,6$ & Netral & 50 & 31,3 & 14,6 & 14,5 & 13,0 & 8,0 & 20,0 \\
\hline $13,7-16,8$ & Setuju & 59 & 36,9 & & & & & \\
\hline $16,9-20,0$ & Sangat Setuju & 40 & 25,0 & & & & & \\
\hline
\end{tabular}

Hasil analisis data kerja keras dalam matapelajaran IPA di SMPN 3 Batanghari pada indikator Selalu Fokus di deskripsikan pada tabel 4 yang memperlihatkan bahwa respon siswa berkategori sangat baik sebanyak 25,0\% (40 dari 160 siswa). Lalu kategori baik sebanyak 36,9\% (59 dari 160 siswa), kategori cukup 31,3\% (50 dari 160 siswa), kategori tidak baik 6,9\% (11 dari 160 siswa) dan kategori sangat tidak baik yaitu 0\% (0 dari 160 siswa). Rata-rata skor yang diperoleh siswa adalah 14,6 dengan skor yang paling banyak diperoleh adalah 13,0 dimana skor minimalnya 8,0 dan skor maksimal 20,0. Dengan demikian berdasarkan hasil analisis data angket tabel 4 yaitu kerja keras dalam matapelajaran IPA di SMPN 3 Batanghari pada indikator ini memperlihatkan bahwa siswa lebih dominan berkategori baik.

Tabel 5 Mengerjakan Semua Tugas Kelas Selesai dengan Baik pada Waktu yang Telah Ditetapkan pada Matapelajaran IPA di SMPN 3 Batanghari

\begin{tabular}{ccccccccc}
\hline Rentang & Kerja Keras & Jumlah & $\%$ & Mean & Median & Modus & Min & Max \\
\hline $2,0-3,6$ & Sangat tidak & 0 & 0 & & & & & \\
$3,7-5,2$ & Setuju & Tidak Setuju & 17 & 10,6 & & & & \\
$5,3-6,8$ & Netral & 39 & 24,4 & 6,9 & 7.0 & 7.0 & 4,0 & 10,0 \\
$6,9-8,4$ & Setuju & 84 & 52,5 & & & & & \\
$8,5-10,0$ & Sangat Setuju & 20 & 12,5 & & & & & \\
\hline
\end{tabular}


Hasil analisis data kerja keras dalam matapelajaran IPA di SMPN 3 Batanghari pada indikator Mengerjakan Semua Tugas Kelas Selesai dengan Baik pada Waktu yang Telah Ditetapkan di deskripsikan pada tabel 5 yang memperlihatkan bahwa respon siswa berkategori sangat baik sebanyak 12,5\% (20 dari 160 siswa). Lalu kategori baik sebanyak 52,5\% (84 dari 160 siswa), kategori cukup 24,4\% (39 dari 160 siswa), kategori tidak baik 10,6\% (17 dari 160 siswa) dan kategori sangat tidak baik yaitu 0\% (0 dari 160 siswa). Rata-rata skor yang diperoleh siswa adalah 6,9 dengan skor yang paling banyak diperoleh adalah 7,0 dimana skor minimalnya 4,0 dan skor maksimal 10,0. Dengan demikian berdasarkan hasil analisis data angket tabel 5 yaitu kerja keras dalam matapelajaran IPA di SMPN 3 Batanghari pada indikator ini memperlihatkan bahwa siswa lebih dominan berkategori baik.

Tabel 6 Tidak Putus Asa dalam Menghadapi Kesulitan dalam Belajar pada Matapelajaran IPA di SMPN 3 Batanghari

\begin{tabular}{ccccccccc}
\hline Rentang & Kerja Keras & Jumlah & $\%$ & Mean & Median & Modus & Min & Max \\
\hline $5,0-9,0$ & Sangat tidak & 0 & 0 & & & & & \\
$9,1-13,0$ & Setuju & Tidak Setuju & 4 & 2.5 & & & & \\
$13,1-17,0$ & Netral & 54 & 33.8 & 18,6 & 19,0 & 20,0 & 11,0 & 25,0 \\
$17,1-21,0$ & Setuju & 75 & 46.9 & & & & \\
$21,1-25,0$ & Sangat Setuju & 27 & 16.9 & & & & \\
\hline
\end{tabular}

Hasil analisis data kerja keras dalam matapelajaran IPA di SMPN 3 Batanghari pada indikator Tidak Putus Asa dalam Menghadapi Kesulitan dalam Belajar di deskripsikan pada tabel 6 yang memperlihatkan bahwa respon siswa berkategori sangat baik sebanyak 16,9\% (27 dari 160 siswa). Lalu kategori baik sebanyak 46,9\% (75 dari 160 siswa), kategori cukup 33,8\% (54 dari 160 siswa), kategori tidak baik 2,5\% (4 dari 160 siswa) dan kategori sangat tidak baik yaitu 0\% (0 dari 160 siswa). Rata-rata skor yang diperoleh siswa adalah 18,6 dengan skor yang paling banyak diperoleh adalah 19,0 dimana skor minimalnya 11,0 dan skor maksimal 25,0. Dengan demikian berdasarkan hasil analisis data angket tabel 6 yaitu kerja keras dalam matapelajaran IPA di SMPN 3 Batanghari pada indikator ini memperlihatkan bahwa siswa lebih dominan berkategori baik.

Tabel 7 Berusaha Menyelesaikan Tugasnya Hingga Tuntas pada Matapelajaran IPA di SMPN 3 Batanghari

\begin{tabular}{|c|c|c|c|c|c|c|c|c|}
\hline Rentang & Kerja Keras & Jumlah & $\%$ & Mean & Median & Modus & Min & Max \\
\hline $4,0-7,2$ & $\begin{array}{l}\text { Sangat tidak } \\
\text { Setuju }\end{array}$ & 0 & 0 & & & & & \\
\hline $7,3-10,4$ & Tidak Setuju & 1 & 0,6 & & & & & \\
\hline $10,5-13,6$ & Netral & 8 & 5,0 & 16,8 & 17.0 & 18.0 & 9,0 & 20,0 \\
\hline $13,7-16,8$ & Setuju & 61 & 38,1 & & & & & \\
\hline $16,9-20,0$ & Sangat Setuju & 90 & 56,3 & & & & & \\
\hline
\end{tabular}

Hasil analisis data kerja keras dalam matapelajaran IPA di SMPN 3 Batanghari pada indikator Berusaha Menyelesaikan Tugasnya Hingga Tuntas di deskripsikan pada tabel 7 yang memperlihatkan bahwa respon siswa berkategori sangat baik sebanyak 56,3\% (90 dari 160 siswa). Lalu kategori baik sebanyak $38,1 \%$ (61 dari 160 siswa), kategori cukup 5,0\% (8 dari 160 siswa), kategori tidak baik 0,6\% (1 dari 160 siswa) dan kategori sangat tidak baik yaitu 0\% (0 dari 160 siswa). Rata-rata skor yang diperoleh siswa adalah 16,8 dengan skor yang paling banyak diperoleh adalah 18,0 dimana skor minimalnya 9,0 dan skor maksimal 20,0. Dengan demikian berdasarkan hasil analisis data angket tabel 7 yaitu kerja keras dalam matapelajaran IPA di SMPN 3 Batanghari pada indikator ini memperlihatkan bahwa siswa lebih dominan berkategori sangat baik.

Tabel 8 Mencipatakan Suasana Belajar yang Memacu Daya Tahan Kerja pada Matapelajaran IPA di SMPN 3 Batanghari

\begin{tabular}{ccccccccc}
\hline Rentang & Kerja Keras & Jumlah & $\%$ & Mean & Median & Modus & Min & Max \\
\hline $2,0-3,6$ & Sangat tidak Setuju & 0 & 0 & & & & & \\
$3,7-5,2$ & Tidak Setuju & 3 & 1.9 & & & & \\
$5,3-6,8$ & Netral & 9 & 5.6 & 8,7 & 9.0 & 10,0 & 4,0 & 10,0 \\
$6,9-8,4$ & Setuju & 51 & 31,9 & & & & \\
$8,5-10,0$ & Sangat Setuju & 97 & 60,6 & & & & \\
\hline
\end{tabular}


Hasil analisis data kerja keras dalam matapelajaran IPA di SMPN 3 Batanghari pada indikator Mencipatakan Suasana Belajar yang Memacu Daya Tahan Kerja di deskripsikan pada tabel 8 yang memperlihatkan bahwa respon siswa berkategori sangat baik sebanyak 60,6\% (97dari 160 siswa). Lalu kategori baik sebanyak 31,9\% (51 dari 160 siswa), kategori cukup 5,6\% (9 dari 160 siswa), kategori tidak baik 1,9\% (3 dari 160 siswa) dan kategori sangat tidak baik yaitu 0\% (0 dari 160 siswa). Rata-rata skor yang diperoleh siswa adalah 8,7 dengan skor yang paling banyak diperoleh adalah 10,0 dimana skor minimalnya 4,0 dan skor maksimal 10,0. Dengan demikian berdasarkan hasil analisis data angket tabel 8 yaitu kerja keras dalam matapelajaran IPA di SMPN 3 Batanghari pada indikator ini memperlihatkan bahwa siswa lebih dominan berkategori sangat baik.

\subsection{Pembahasan}

Bentuk penanaman pendidikan karakter di SMPN 3 Batanghari terintegrasi kedalam visi dan misi sekolah yang diimplementasikan melalui proses pembelajaran di matapelajaran IPA dan melalui kerja sama dengan orang tua siswa dan masyarakat. Pendidikan karakter dimaknai dengan sistem penanaman nilai-nilai karakter kepada siswa yang meliputi komponen penetahuan, kesadaran, atau kemauan dan tindakan untuk melaksanakan nilai-nilai tersebut. Kerja keras merupakan salah satu dari 18 karakter yang harus ditanamkan pada diri siswa. Kerja keras adalah perilaku yang menunjukkan upaya sungguhsungguh dalam mengatasi berbagai hambatan belajar dan tugas, serta menyelesaikan tugas dengan sebaikbaiknya [19]. Pelaksanaan nilai kerja keras dapat dituangkan dengan cara belajar keras dan mengerjakan tugas hingga selesai tanpa mengenal lelah. Berdasarkan hasil analisis data kerja keras pada matapelajaran IPA yang diperoleh memperlihatkan bahwa siswa SMPN 3 Batanghari pada ke enam indikator tersebut berada pada kategori dari baik hingga sangat baik yang mempresentasikan bahwa secara keseluruhan siswa di sekolah tersebut telah baik dalam menanamkan kerja keras pada matapelajaran IPA.

\subsubsection{Menciptakan Kondisi Etos Kerja dan Pantang Menyerah pada Matapelajaran IPA di SMPN 3 Batanghari}

Indikator kerja keras tersebut merupakan suatu perangkat keyakinan seseorang untuk terus melakukan usaha sampai tercapai apa yang diinginkan tanpa menyerah. Dalam hal tersebut, bukannya terus menerus bekerja tanpa ada jeda, hanya saja bekerja yang lebih gigih dari biasanya. Meskipun dalam suatu usaha mendapatkan halangan, hingga menemui kegagalan berkali-kali, orang yang jiwanya sudah tertanam karakter kerja keras tidak akan mudah menyerah. Siswa di SMPN 3 Batanghari dalam proses pembelajaran telah menunjukkan usaha untuk tidak menyerah, hal ini dapat dilihat dari jawaban siswa ketika mengisi kuesioner yaitu mengerjakan soal-soal IPA hingga menemukan jawaban benar. Rasa ingin tahu mendorong siswa agar terus menerus berusaha mencari tahu segala sesuatu yang berkaitan dengan IPA dengan sendirinya tanpa perintah atau tugas dari guru hal ini menunjukan bahwa siswa memiliki kerja keras yang baik dalam matapelajaran IPA. Rasa ingin tahu merupakan sikap dan tindakan yang selalu berupaya untuk mengetahui lebih mendalam dan meluas dari sesuatu yang dipelajarinya, dilihat, dan didengar [20]. [21-24] Sikap itu sendiri dapat kita artikan kepribadian yang dimiliki semua orang untuk memotivasikan dirinya sendiri. Sikap merupakan salah satu faktor yang mempengaruhi proses pembelajaran yang berasal dari dalam diri siswa [2528].

\subsubsection{Selalu Fokus dalam Matapelajaran IPA}

Pada indikator ini siswa SMPN 3 Batanghari dominan berkategori baik artinya secara keseluruhan siswa fokus dalam proses pembelajaran IPA, hal ini dapat dilihat pada saat siswa menjawab kuesioner yaitu. When students are focused on learning, the material delivered by the teacher will be easy to understand because students' minds are focused on only one point [29-30]. Cara lain yang harus dilakukan oleh seorang guru ialah melakukan sebuah inovasi dalam proses pembelajaran salah satunya adalah metode diskusi [3132]. [33] Diskusi yang dilakukan antara gurusiswa dalam pembelajaran, mengilustrasikan bahwa interaksi sosial yang berupa diskusi ternyata mampu memberikan kesempatan pada siswa untuk mengoptimalkan proses belajarnya.

\subsubsection{Mengerjakan Semua Tugas Kelas Selesai dengan Baik pada Waktu yang telah Ditetapkan}

Indikator ini menekankan bahwa siswa secara sukarela tanpa ada paksaan mampu mengerjakan semua tugas tepat pada waktunya. Artinya siswa juga bersungguh-sungguh untuk bisa menyelesaikan tugas nya. Pada indikator ini siswa SMPN 3 Batanghari dominan berkategori baik. Dengan kata lain secara keseluruhan siswa sudah mengerjakan tugas dengan baik. Hal ini dapat dilihat dari jawaban kuesioner yang telah diberikan kepada siswa. Keseriusan dalam mengerjakan tugas ini di motivasikan oleh semangat yang dimiliki siswa. Tanda-tanda siswa yang memiliki motivasi yang baik berasal dari sikap yang dimilikinya. 
Sikap itu sendiri telah tertanam didalam diri siswa [34-36]. Selanjutnya faktor orang tua yang memberikan pengarahan serta motivasi ini menjadikan siswa lebih semangat dalam mengerjakan tugas yang diberikan kepada siswa [37-38].

\subsubsection{Tidak Putus Asa dalam Menghadapi Kesulitan dalam Belajar}

Pada indikator ini siswa dominan berkategori baik. Hal ini terwujud melalui usaha siswa yang berusaha mencari buku atau bahan belajar IPA di perpustakaan. Lectures expect their text books to enrich student learning materials [10]. Dengan mencari buku yang digunakan sebagai bahan belajar sendiri di perpustakaan dapat menambah wawasan tambahan terkait matapelajaran IPA di luar dari bahan ajar yang telah diberikan guru dilihat dari usaha siswa dalam memperkaya pengetahuan menunjukan bahwa siswa memiliki sikap kerja keras terhadap matapelajaran IPA

\subsubsection{Berusaha menyelesaikan tugasnya hingga tuntas}

Pada indikator ini siswa dominan berkatgeori sangat baik. Hal ini dapat dilihat dari jawaban kuesioner yaitu Saya berusaha mengerjakan soal IPA sampai menemukan jawaban yang benar dimana siswa menjawab sangat setuju yang artinya telah tercipta bentuk keinginan dan kemandirian untuk belajar serius dalam menghadapi persoalan matapelajaran IPA [39-40]. Bentuk kemandirian siswa dapat dilihat dari pengerjaan tugas atau PR yang diberikan oleh guru serta bagaimana siswa tidak bergantung pada orang lain dan meyakini kemampuannya sendiri [41].

\subsubsection{Mencipatakan suasana belajar yang memacu daya tahan kerja}

Pada indikator ini siswa dominan berkategori sangat baik yang artinya siswa memiliki komitmen didalam dirinya untuk sungguh-sungguh belajar IPA dan membiasakan diri agar tidak merasa bosan. Komitmen yang tertanam didalam diri siswa akan memicu timbulnya minat untuk selalu mempelajari IPA. Siswa yang berminat dengan dengan konsep IPA, mereka akan belajar lebih giat untuk memahaminya [41]. Menciptakan suasana baru dalam belajar ini merupakan implikasi atau dampak dari pembelajaran yang dirasakan oleh siswa. Biasanya implikasi ini dilihat dari sukanya siswa terhadap mata pelajaran tersebut, sehingga siswa menciptakan suasana baru dalam belajar [42].

\section{KESIMPULAN}

Berdasarkan hasil penelitian yang telah diperoleh mengenai kerja keras siswa dalam matapelajaran IPA di SMPN 3 Batanghari melalui enam indikator yaitu: Menciptakan Kondisi Etos Kerja dan Pantang Menyerah dalam matapelajaran IPA dominan berkategori baik, Selalu Fokus dalam Matapelajaran IPA dominan berkategori baik, Mengerjakan Semua Tugas Kelas Selesai dengan Baik pada Waktu yang Telah Ditetapkan dalam Matapelajaran IPA dominan berkategori baik, Tidak Putus Asa dalam Menghadapi Kesulitan dalam Belajar dalam Matapelajaran IPA dominan berkategori baik, Berusaha Menyelesaikan Tugasnya Hingga Tuntas dalam Matapelajaran IPA dominan berkategori sangat baik, dan Menciptakan Suasana Belajar yang Memacu Daya Tahan Kerja dominan berkategori sangat baik. Dengan kata lain siswa di SMPN 3 Batanghari secara keseluruhan telah menanamkan karakter kerja keras dalam matapelajaran IPA

\section{UCAPAN TERIMA KASIH}

Peneliti mengucapkan terimakasih kepada kepala sekolah dan guru serta kepada siswa-siswi SMPN 3 Batanghari yang telah memberikan izin untuk melakukan penelitian.

\section{REFENRENSI}

[1] M. Amri, "Urgensi Pembelajaran Bagi Pengembangan Karakter Akademik Mahasiswa Pendidikan Tinggi, Lentera Pendidikan," vol. 16, no. 2,pp. 139-150. Desember 2013

[2] Astalini, D. A. Kurniawan, \& Sumaryanti, "Sikap Siswa Terhadap Mata pelajaran Fisika di SMAN Kabupaten Batanghari," Jurnal Ilmu Pendidikan Fisika, vol. 3, no. 2, pp. 59-64. 2018

[3] D. A. Kurniawan, \& A. Astalini,"EVALUASI SIKAP SISWA SMP TERHADAP IPA DI KABUPATEN MUARO JAMBI," JURNAL ILMIAH DIDAKTIKA: Media Ilmiah Pendidikan dan Pengajaran, vol. 19, no. 1, pp. 124-139. 2019

[4] Astalini, D.A. Kurniawan, \& L.Z.N. Farida, "Deskripsi sikap siswa SMA di Batanghari berdasarkan indikator normalitas ilmuwan, adopsi dari sikap ilmiah, ketertarikan memperbanyak waktu, dan ketertarikan berkarir di bidang fisika," JRKPF UAD, vol. 5, no. 2, pp. 73-80. 2018 
[5] Syahrial, et al., "Analysis of Ethnolinguistic Knowledge of Elementary School Teachers in Indonesia," Journal of Education and Practic, vol. 10., no. 2, pp. 19-25. 2019 Tersedia di https://www.iiste.org/Journals/index.php/JEP/article/view/46279/47782.

[6] A. Astalini, $d k k$., "Identifikasi Sikap Peserta Didik terhadap Mata Pelajaran Fisika di Sekolah Menengah Atas Negeri 5 Kota Jambi," UPEJ Unnes Physics Education Journal, vol. 8, no. 1, pp. 34-43. 2019

[7] J. W. Creswell, "Educational Research Planning, Conducting and Evaluating Quantitative dan Qualitative Researc,". Lincoln: University of Nebraska. 2015

[8] Darmaji, D. A. Kurniawan, \& A. Suryani, "Effectiveness of Basic Physics II Practicum Guidelines Based On Science Process Skills," Jurnal Ilmu Pendidikan fisika, vol. 4, no. 1, pp. 1-7. 2019

[9] Febrianshari, $d k k$., "Analisis Nilai-nilai Pendidikan Karakter dalam Pembuatan Dompet Punch Zaman Now," Jurnal Pemikiran dan Pengembangan SD, vol. 6 no. 1, pp. 88-95.2018

[10] Miller, et al., "The Meaning and Measurement of Work Ethic: Construction and Initial Validation of a Multidimensional Inventory," Journal of Vocational Behaviour, vol. 24, no. 50, pp. 1-39. 2001

[11] D. A. Nafiati, "Motivation, Creativity, and Self- Confidence as Forming Factors of Economic Learning Autonomy," Dinamika Pendidikan, vol. 12, no. 2, pp. 182-195. 2018 https://doi.org/10.15294/dp.v12i2.13566.

[12] L. Nuryati, M. Diantoro, \& S. Zubaidah, “Analisis Kemampuan Berpikir Kritis Siswa SMP," Jurnal Penelitian Dan Pengembangan, vol. 3, no. 2, pp. 155-158. 2018 https://doi.org/10.23971/eds.v5i2.732.

[13] M.A. Putri \& S. Harto, "Promoting Character Education in Efl Classroom: Using Children 'S Literature As a Teaching Material," vol. 5, no. 2, pp. 163-169. 2017

[14] M. Saleh, "Pengaruh Motivasi, Faktor Keluarga, Lingkungan Kampus dan Aktif Berorganisasi Terhadap Prestasi Akademik," Jurnal Phenomenon, vol.4, no.2, pp. 109-141. 2018

[15] N. Walliman, Nicholas, "Research Methods The Basics," Routledge : New York. 2011

[16] Djaali \& P. Mulyono, "Pengukuran dalam Bidang Pendidikan," Universita Negri Jakarta : Intramedia. 2004

[17] Slamet, et al., "The Development of Text Book to Write Story Based on Character Education in Contextual Learning," International Journal on Studies in English Language and Literature (IJSELL), vol. 3, no.7, pp. 43-50. 2015

[18] O. Suhadi, “Penguatan Pendidikan Karakter (PPK), ” Jakarta: Erlangga. 2018

[19] A. Susilawati, H. Hernani, \& P. Sinaga, "The Application of Project-Based Learning Using Mind Maps To Improve Students' Environmental Attitudes Towards Waste Management in Junior High Schools," International Journal of Education, vol. 9, no. 2, pp. 120. 2017 https://doi.org/10.17509/ije.v9i2.5466.

[20] D. A. Kurniawan,"Students' attitude towards natural sciences," Int. J. Eval. \& Res. Educ, vol. 8, no. 3, pp. 455460.2019

[21] Maison, $d k k$., "Deskripsi Sikap Siswa SMA Negeri Pada Mata Pelajaran Fisika. 2018

[22] Maison, Darmaji, Astalini, D. A. Kurniawan, and P. S. Indrawati, "SCIENCE PROCESS SKILLS AND MOTIVATION", oaihssr, vol. 7, no. 5, pp. 48-56, Sep. 2019. https://doi.org/10.18510/hssr.2019.756

[23] D. Darmaji, "A study relationship attitude toward physics, motivation, and character discipline students senior high school, in Indonesia," International Journal of Learning and Teaching, vol. 11, no. 3, pp. 99-109. 2019

[24] Astalini, D. A. Kurniawan, \& S. Sumaryanti, "Sikap Siswa Terhadap Pelajaran Fisika di SMAN Kabupaten Batanghari,” JIPF (Jurnal Ilmu Pendidikan Fisika), vol. 3, no. 2, pp. 59-64. 2018

[25] Astalini, M., Ikhlas, \& D. A. Kurniawan, "Pengembangan Instrumen Sikap Mahasiswa Terhadap Mata Kuliah Fisika Matematika," 2018

[26] Maison, et al., "Student's Attitude Description Toward Physics On Secondary School," Edusains, vol. 10, no. 1, pp. 160-167. 2018

[27] Jufrida, W. Kurniawan, Astalini, Darmaji, $d k k$., "Students' attitude and motivation in mathematical physics," International Journal of Evaluation and Research in Education (IJERE), vol. 8, No. 3, pp. 401-408 ISSN: 22528822. 2019. http://doi.org/10.11591/ijere.v8i3.20253

[28] Darmaji, et al., "An Identification of Physics Pre-Service Teachers' Science Process Skills Through Science Process Skills-Based Practicum Guidebook," Jurnal Ilmiah Pendidikan Fisika Al-Biruni, vol. 7, no. 2, pp. 239-245. 2018 https://doi.org/10.24042/jipfalbiruni.v7i2.2690

[29] D.A. Kurniawan, N. Amalina, M. Subandiyo, Syahrial, \& Asrial, "Description of Elementary Teacher Education Program's Student: Mapping Indonesian Language Competence for Prospective Teacher," The Educational Review, USA, vol. 3, no. 2, pp. 21-27. 2019

[30] L. Maretika, Darmaji, D. A. Kurniawan, S. Syahrial, \& Asrial, "ANALISIS KOMPETENSI PEDAGOGIK DAN KOMPETENSI IPA TERHADAP CALON GURU SEKOLAH DASAR PGSD FKIP UNIVERSITAS JAMBI," Jurnal DIDIKA: Wahana Ilmiah Pendidikan Dasar, vol. 4, no. 2, pp. 41-49. 2018

[31] Syahrial, et al., "Increased Behavior of Students' Attitudes to Cultural Values Using the Inquiry Learning Model Assisted by Ethnoconstructivism,” Journal of Educational Science and Technology (EST), vol. 5, no. 2. 2019 
[32] D. Suryadi, "Menciptakan proses belajar aktif: Kajian dari sudut pandang teori belajar dan teori didaktik," Bandung: Tidak diterbitkan. 2010

[33] Astalini, dkk., "Sikap Terhadap Mata Pelajaran IPA di SMP Se-Kabupaten Muaro Jambi," Lentera Pendidikan: Jurnal Ilmu Tarbiyah dan Keguruan, vol. 21, no. 2, pp. 214-227. 2019

[34] A. ., D. A. Kurniawan, D. ., L. R. Sholihah, and R. Perdana, "CHARACTERISTICS OF STUDENTS' ATTITUDE TO PHYSICS IN MUARO JAMBI HIGH SCHOOL”, oaihssr, vol. 7, no. 2, pp. 91-99, Mar. 2019. https://doi.org/10.18510/hssr.2019.7210

[35] Astalini, Darmaji, D. A.Kurniawan, \& D. Destianti, "Description of the Dimensions Attitudes towards Science in Junior High School at Muaro Jambi,” Int. J. Sci. Basic Appl. Res.(IJSBAR), vol. 47, no. 1, pp. 1-11. 2019

[36] Astalini, dkk., "Sikap Mahasiswa Pendidikan Fisika Pada Mata Kuliah Fisika Matematika III Universitas Jambi," Jurnal Pendidikan IPA Indonesia.

[37] Darmaji, et al., "Students' perceptions of electronic's module in physics practicum," Journal of Education and Learning (EduLearn), vol. 13, no. 2, pp. 288-294. 2019

[38] A. R. Putri, M. Maison, \& D.Darmaji, "KERJASAMA DAN KEKOMPAKAN SISWA DALAM PEMBELAJARAN FISIKA DI KELAS XI MIPA SMA NEGERI 3 KOTA JAMBI," EduFisika: Jurnal Pendidikan Fisika, vol. 3, no. 2, pp. 32-40. 2018

[39] D. Darmaji, A. Supriyanto, \& A. Timan, "SISTEM PENJAMINAN MUTU INTERNALSEKOLAH UNTUK MENINGKATKAN MUTU LULUSAN," JMSP (Jurnal Manajemen dan Supervisi Pendidikan), vol. 3, no. 3, pp. 130-136. 2019

[40] D. A. Kurniawan, "IMPLIKASI SOSIAL, PENYELIDIKAN ILMIAH, DAN KESENANGAN BELAJAR SISWA PADA MATA PELAJARAN FISIKA," Jurnal Pendidikan Indonesia.

[41] Sapulette, $d k k$.,"Peningkatan Karakter Siswa Kelas IV SD Negeri 16 Ambon Melalui Pembelajaran PPKN dengan Media Cerita Rakyat," Harmoni Sosial Jurnal Pendidikan IPS, vol. 3, no. 2, pp. 150-165. 2016

[42] S. Syahrial, et al., "The impact of etnocontructivism in social affairs on pedagogic competencies," Int. J. Eval. \& Res. Educ, vol, 8, no. 3, pp. 409-416. 2019 